\title{
Slope stability analysis considering seepage and stress coupling under water level fluctuation
}

\author{
Zhou YiLiang ${ }^{1, *}$, Li Ming $^{1}$, and Li ZiLong ${ }^{1}$ \\ ${ }^{1}$ School of Civil Engineering, University of south China, Hengyang, 421001, China
}

\begin{abstract}
The reservoir water level fluctuation is an important factor inducing the reaction of pore-water pressure, seepage and at last resulting in instability and failure of the slope. A typical homogeneous slope is conducted as an example in this paper, the seepage and stress coupling effect is considered, and the slope stability calculation and analysis are carried out by using the finite element stress method. The results demonstrate that the factor of safety increases with the reservoir water level rises, and then gradually changes from decrease to stabilization. It should be noted that the factor of safety decreases slightly during the initial stage of water level rising at the speed of $0.2 \mathrm{~m} / \mathrm{d}$, which the slope will probably lose its stability. On the other, the factor of safety changes from decrease to increase along with the reservoir water level drawdown, and then gradually tends to stabilization. There is a minimum factor of safety when the water level is at about $1 / 4$ of the slope height, and the minimum factor of safety decreases with increasing drawdown speed, just as the factor of safety decreases from 0.83 to 0.73 when the drawdown speed is increased from $0.20 \mathrm{~m} / \mathrm{d}$ to $5.0 \mathrm{~m} / \mathrm{d}$.
\end{abstract}

\section{Introduction}

According to the 2019 Statistic Bulletin on China Water Activities, by the end of 2019, the number of reservoirs in China reached 98112 , with a total storage capacity of 898.3 billion $\mathrm{m}^{3}$. It provides an important guarantee for water storage, irrigation, power generation and water supply in China. Therefore, the reservoir water level fluctuation is noted as the main factor resulting in instability and failure of the slope, and the accurate slope stability analysis under different water level fluctuation is meaningful for ensuring safety of the reservoir projects [1$3]$.

Ding et al. analyzed the deformation trends and the failure process of Nanqiaotou landslide in Three Gorges Reservoir area, and found that the deformation of the slope above the water level gradually increases with respect to the reservoir water level rises, and the direction and magnitude of the deformation were determined by the water pressures jointly coming from the outside and inside slope[4]. Liu et al. described the effect of pore-water pressure on soil stresses by using Mohr-Coulomb strength criterion, and indicated that the slope stability changed from decrease to increase due to pore-pressure when reservoir water level rose from the foot to the top of the slope[5]. Yang et al. assumed that the fluctuation range of water level was located in lower parts of the slope, and found that the whole stability of the slope was decreased with the water level rose, while its local stability was changed from decrease to increase with the reservoir water level rose[6]. Lin et al. considered the seepage field of landslide to investigate the stability of Sanmendong landslide under different fluctuation speeds of reservoir water, and found the maximum slope stability increased with the increased reservoir water rise speed[7].

Liao et al. employed numerical modeling to investigate the relationship between landslide stability and seepage coefficient, drawdown speed in the Three Gorges Reservoir area[8]. Wang et al. used unsaturatedunsteady seepage theory to analyze the variation characteristics of the seepage field and slope stability when the water level rapid drawdown[9]. Li et al. evaluated the landslide stability under different reservoir water level drawdown speed, and found the landslide stability decreased with the increase of the reservoir water level drawdown speed[10].

As can be seen from the above discussion, the preliminary relationship between the slope stability and reservoir water level rise or drawdown were obtained. It needs further study quantitative relationship between the slope stability and reservoir water level fluctuation. At the same time, it should be noted that the change of seepage field will affect the change of stress field and vice versa, which the interaction of seepage and stress cannot be ignored. Therefore, the present study considered the seepage and stress coupling effect, and the slope stability calculation and analysis under different water level fluctuation are carried out by using the finite element stress method.

\footnotetext{
*Corresponding author:940387856@qq.com
} 


\section{Computing theory}

\subsection{Coupled analysis of seepage-stress}

Based on the continuous motion equation of groundwater, the two-dimensional seepage equation is given by Darcy's law:

$$
\frac{k_{x}}{\gamma_{w}} \frac{\partial^{2} u_{w}}{\partial x^{2}}+\frac{k_{y}}{\gamma_{w}} \frac{\partial^{2} u_{w}}{\partial y^{2}}+\frac{\partial \theta_{w}}{\partial t}=0
$$

The coupled analysis for saturated-unsaturated soils using incremental displacement and incremental porewater pressure as field variables. The volumetric water content in equation(1) is given by the following expressions[13]:

$$
\theta_{w}=\frac{\beta}{3} \varepsilon_{v}-\omega u_{w}
$$

And

$$
\begin{gathered}
\beta=\frac{E}{H} \frac{1}{(1-2 v)}=\frac{3 K_{B}}{H} \\
\omega=\frac{1}{R}-\frac{3 \beta}{H}
\end{gathered}
$$

Where $K_{B}$ is the bulk modulus, $H$ is the unsaturated soil modulus for soil structure with respect to matrix suction, $R$ is a modulus relating the change in volumetric water content with change in matric suction. It is assumed that the material properties remain constant within a time increment, and this equation becomes:

$$
\Delta \theta_{w}=\beta \Delta \varepsilon_{v}-\omega \Delta u_{w}
$$

The seepage equation can be formulated for finite element analysis by using the principle of virtual work. If virtual pore-water pressures $u_{w}^{*}$ are applied to the seepage equation, gives:

$$
\int u_{w}^{*}\left[\frac{k_{x}}{\gamma_{w}} \frac{\partial^{2} u_{w}}{\partial x^{2}}+\frac{k_{y}}{\gamma_{w}} \frac{\partial^{2} u_{w}}{\partial y^{2}}+\frac{\partial \theta_{w}}{\partial t}\right] d V=0
$$

Applying integration by parts and substituting equation (5) to equation(6) gives:

$$
\begin{aligned}
& -\int\left[\frac{k_{x}}{\gamma_{w}} \frac{\partial u_{w}^{*}}{\partial x} \frac{\partial u_{w}}{\partial x}+\frac{k y}{\gamma_{w}} \frac{\partial u_{w}^{*}}{\partial y} \frac{\partial u_{w}}{\partial y}\right] d V+\int u_{w}^{*} \frac{\partial\left(\beta \varepsilon_{v}-\omega u_{w}\right)}{\partial t} d V \\
& =\int u_{w}^{*} V_{n} d V
\end{aligned}
$$

Where $V_{n}$ is the boundary flux.Using finite element approximations, equation can be written as:

$$
\begin{gathered}
-\int \frac{1}{\gamma_{w}}[B]^{T}\left[K_{w}\right][B]\left\{u_{w}\right\} d V-\int\langle N\rangle^{T}\langle N\rangle\left\{\frac{\partial\left(\omega u_{w}\right)}{\partial t}\right\}+ \\
\int\langle N\rangle^{T}\{m\}^{T}[B]\left\{\frac{\partial(\beta \delta)}{\partial t}\right\} d V=\int\langle N\rangle^{T} V_{n} d V
\end{gathered}
$$

Where:

$$
\begin{gathered}
\int[B]^{T}\left[K_{w}\right][B] d V=\left[K_{f}\right] \\
\langle N\rangle^{T}\langle N\rangle=\left[M_{N}\right] \\
\int\langle N\rangle^{T}\{m\}^{T}[B] d V=\left[L_{f}\right]
\end{gathered}
$$

with: $[B]$ is the gradient matrix, $\left[K_{w}\right]$ is the hydraulic conductivity matrix, $\left[K_{f}\right]$ is the element stiffness matrix, $\langle N\rangle$ is the row vector of shape functions, $\left[M_{N}\right]$ is the mass matrix, $\left[L_{f}\right]$ is the coupling matrix for flow, $\{m\}^{T}$ is the isotropic unit tensor, and $\delta$ is the nodal displacement.

Integrating equation(8) from time $t$ to time $t+\Delta t$ and the backward time-stepping scheme is used, gives,

$$
\begin{aligned}
& \beta\left[L_{f}\right]\{\Delta \delta\}-\left(\frac{\Delta t}{\gamma_{w}}\left[K_{f}\right]+\omega\left[M_{N}\right]\right)\left\{\Delta u_{w}\right\}= \\
& \Delta t\left(\left.\{Q\}\right|_{t+\Delta t}+\left.\frac{1}{\gamma_{w}}\left[K_{f}\right]\left\{u_{w}\right\}\right|_{t}\right)
\end{aligned}
$$

The finite element equilibrium equation for saturatedunsaturated soils are formulated:

$$
[K]\{\Delta \delta\}+\left[L_{d}\right]\left\{\Delta u_{w}\right\}=\{F\}
$$

Where $\left[K_{w}\right]$ is the stiffness matrix, $\left[L_{d}\right]$ is the coupling matrix.

In summary, the coupled analysis model of seepagestress is built by the combined equation(9) and equation(10).

\section{2 stability analysis}

In the calculation of slope stability, the factor of safety is calculated based on the finite element stress method. Firstly, the stress of $\sigma_{x}, \sigma_{y}$ and $\tau_{x y}$ in each element are obtained from coupled analysis of seepage-stress. The substrate normal stress and shear stress of the soil slices are obtained by method of Mohr's stress circle, and the effective shear strength is calculated by the substrate normal stress. Then the slide force and anti-sliding force are calculated by multiplying the sliding shear stress and the effective shear strength by the width of the soil slice respectively. Finally, the factor of safety is obtained by combining the total length of sliding surfaces. It is written as:

$$
F S=\frac{\sum S_{r}}{\sum S_{m}}
$$

Where $S_{r}$ is the total anti-sliding force along the entire sliding surface, $S_{m}$ is the total sliding force along the entire sliding surface.

\section{A Case Study}

In this paper, a typical homogeneous slope is selected to analyze the slope stability calculation and analysis under different water level fluctuation. The geometric shape is illustrated in Figure 1, and the soil parameters are presented in Table 1. 


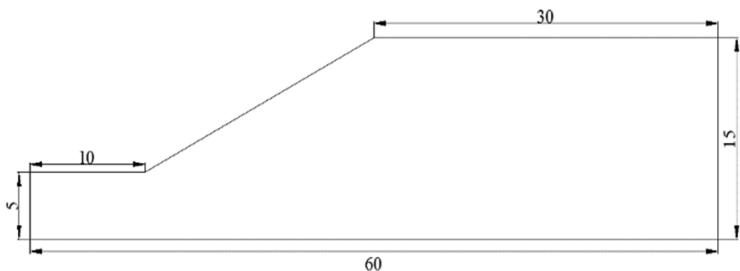

Figure 1. A typical sketch of the homogeneous slope(unit: $\mathrm{m})$.

Table1. Soil parameters of the slope.

\begin{tabular}{cc}
\hline material parameters & value \\
\hline volume-weight $\left(\mathrm{kN} / \mathrm{m}^{3}\right)$ & 20 \\
internal friction angle $\left({ }^{\circ}\right)$ & 19.6 \\
cohesive force $(\mathrm{kPa})$ & 3 \\
saturated water content $(\%)$ & 22 \\
Poisson's ratio & 0.25 \\
elastic modulus $(\mathrm{MPa})$ & 10 \\
seepage coefficient $(\mathrm{m} / \mathrm{s})$ & $2 \times 10^{-6}$ \\
\hline
\end{tabular}

Three modules of Seep/W, Sigma/W and Slope/W in Geo-Studio are used to analyze the slope stability based on the seepage and stress coupling effect. Firstly, the relationship between seepage coefficient and matric suction is obtained by using Seep/W module according to the soil-water characteristic curve, as illustrated in Figure 2 and Figure 3, and the initial seepage field is calculated. Then the initial stress field is obtained from Sigma /W and the initial seepage field obtained from Seep/W, which as the initial conditions to solve the coupled equations, and the changes in seepage field, stress field and displacement field at each time step are obtained. Finally, the porepressure and stress data are imported into Slope/W module, and the finite element stress method is used to conduct dynamic analysis on the slope stability.

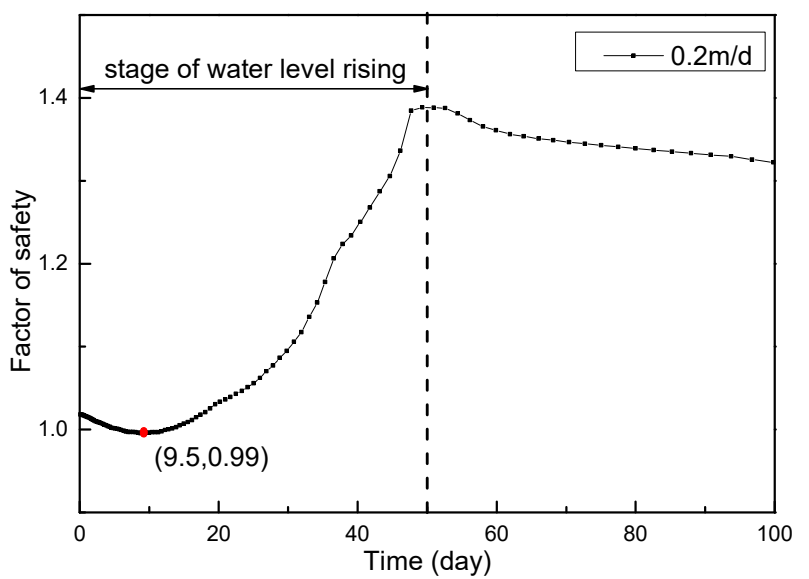

(a). Relationship between safety factor and time when the water level rise speed is $0.2 \mathrm{~m} / \mathrm{d}$.

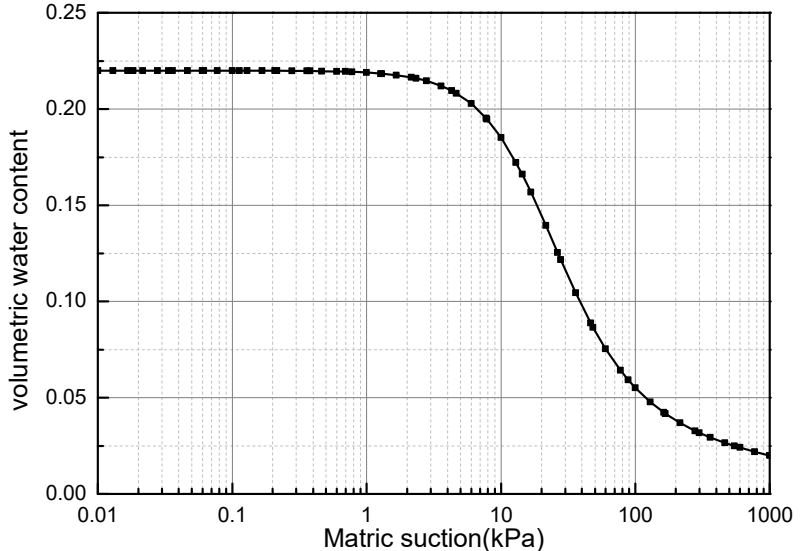

Figure 2. Curve of soil water characteristics.

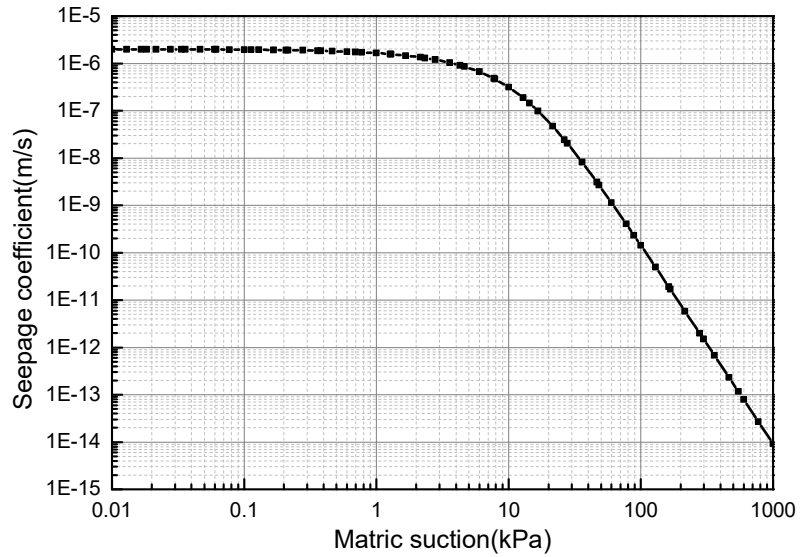

Figure 3. Curve of seepage coefficient.

\subsection{Slope stability analysis with the reservoir water level rise}

The rising speed of reservoir water level is $0.2 \mathrm{~m} / \mathrm{d}, 1.0 \mathrm{~m} / \mathrm{d}$, $5.0 \mathrm{~m} / \mathrm{d}$ are designed, where the reservoir water level rise from the foot at $5.0 \mathrm{~m}$ to the top at $15.0 \mathrm{~m}$ of the slope. It is assumed that the seepage coefficient of the slope is the same in each case, and the total time step is 150 days.

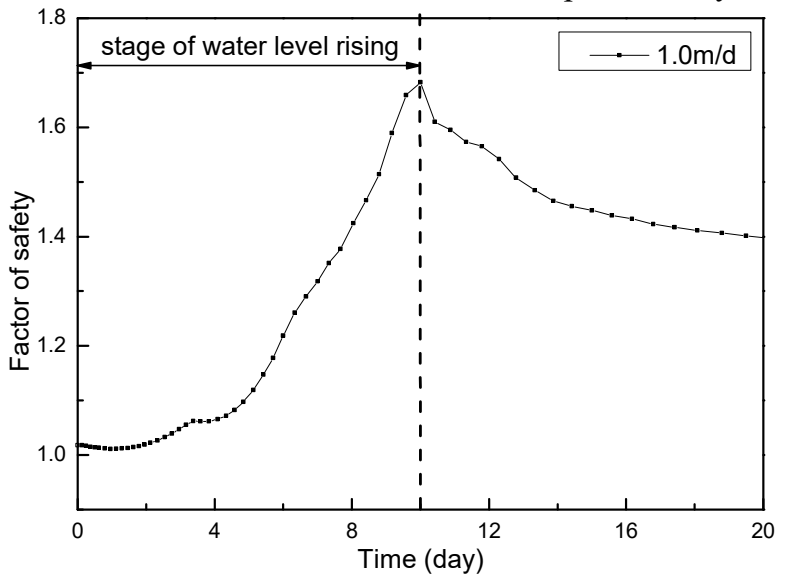

(b). Relationship between safety factor and time when the water level rise speed is $1.0 \mathrm{~m} / \mathrm{d}$. 


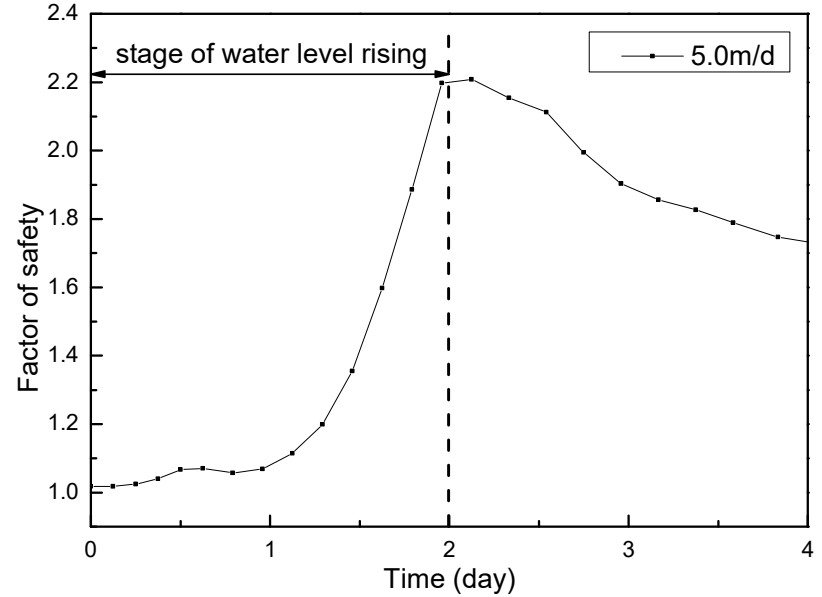

(c). Relationship between safety factor and time when the water level rise speed is $5.0 \mathrm{~m} / \mathrm{d}$.

Figure speed is 5.0

Figure 4(a) to Figure 4(c) present the variation of safety factor with time under different reservoir water level rise speeds. It is found that the factor of safety increases with the reservoir water level rises, as well as the value reaches the maximum when the reservoir water level rises to the top of slope, then gradually changes from decrease to stabilization. During the process, the rise speed of the reservoir water level is higher than the rise speed of groundwater in the slope, resulting in the water flowing from the outside to the inside of the slope, and inducing the hydrodynamic pressure which is conducive to the stability of the slope. On the other hand, the flooded area of the slope will gradually increase with the groundwater rise, which is not conducive to the stability of the slope. Therefore, because of the great delay time of the process of the groundwater rise, resulting in the hydrodynamic pressure having an evident greater influence than the flooded area, the factor of safety present an increased trend. Then the flooded area gradually increases and the hydrodynamic pressure also gradually decreases with groundwater rise, resulting in the factor of safety decrease, and trend to stabilization when the water level is the same high on the inside and outside of the slope.

However, the factor of safety changes from decrease slightly to increase during the initial stage of water level rising at the speed of $0.2 \mathrm{~m} / \mathrm{d}$. The reason is that the

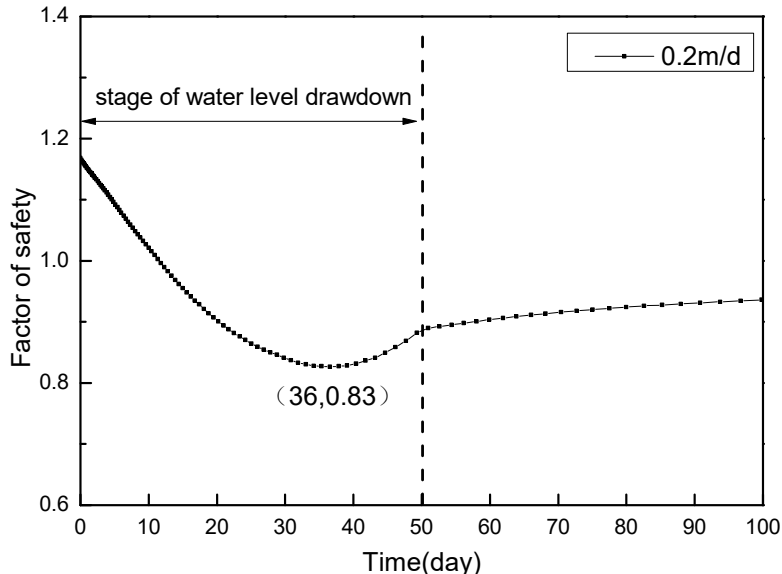

(a). Relationship between safety factor and time when the water level drawdown speed is $0.2 \mathrm{~m} / \mathrm{d}$.

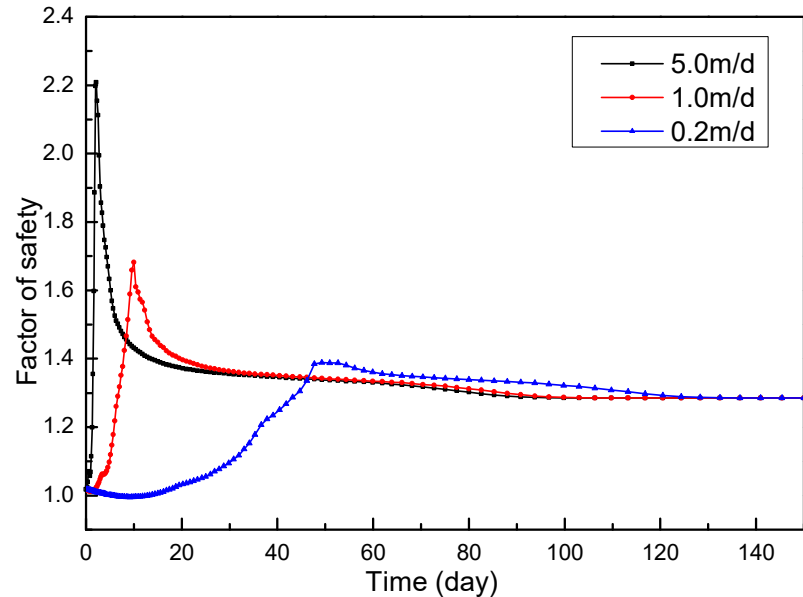

(d). Comparison of the safety factor change with time under different water level rise speeds.

hydrodynamic pressure grows relatively slowly when the reservoir water level rise speed is very lower, the flooded area has an evident greater influence than the hydrodynamic pressure in the initial stage. Therefore, it is also pointed out that the slope will probably lose its stability because of the disadvantageous action of the flooded area during the initial stage of water level rising at a low speed.

Figure 4(d) shows that the shorter time and higher maximum value of the safety factor arrives with the greater rising speed of the reservoir water level. The reason is that the hydrodynamic pressure grows relatively fast and large when the reservoir water level rise speed is very higher. It is also show that the higher speed of the reservoir water level rising, the more favorable to the stability of slope.

\subsection{Slope stability analysis with the reservoir water level drawdown}

In the same way, the drawdown speed of reservoir water level is $0.2 \mathrm{~m} / \mathrm{d}, 1.0 \mathrm{~m} / \mathrm{d}, 5.0 \mathrm{~m} / \mathrm{d}$ are designed, where the reservoir water level drawdown from the top at $15.0 \mathrm{~m}$ to the foot at $5.0 \mathrm{~m}$ of the slope. It is assumed that the seepage coefficient of the slope is the same in each case, and the total time step is 150 days.

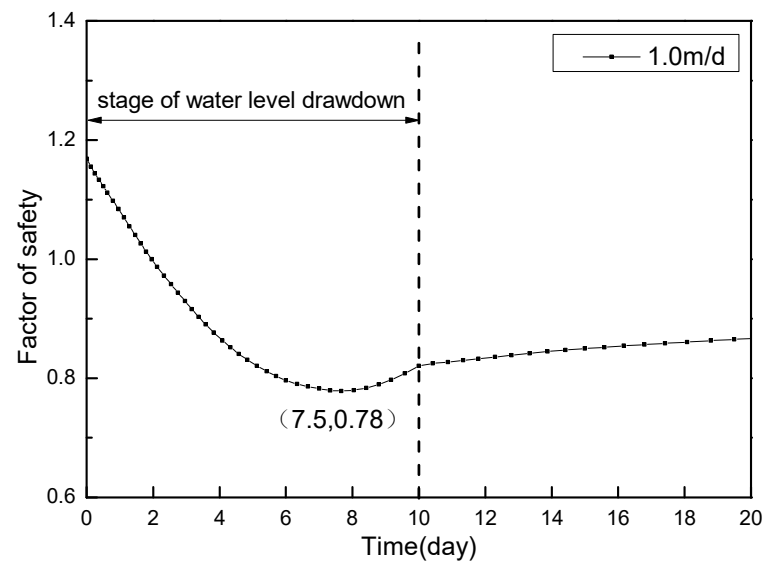

(b). Relationship between safety factor and time when the water level drawdown speed is $1.0 \mathrm{~m} / \mathrm{d}$. 


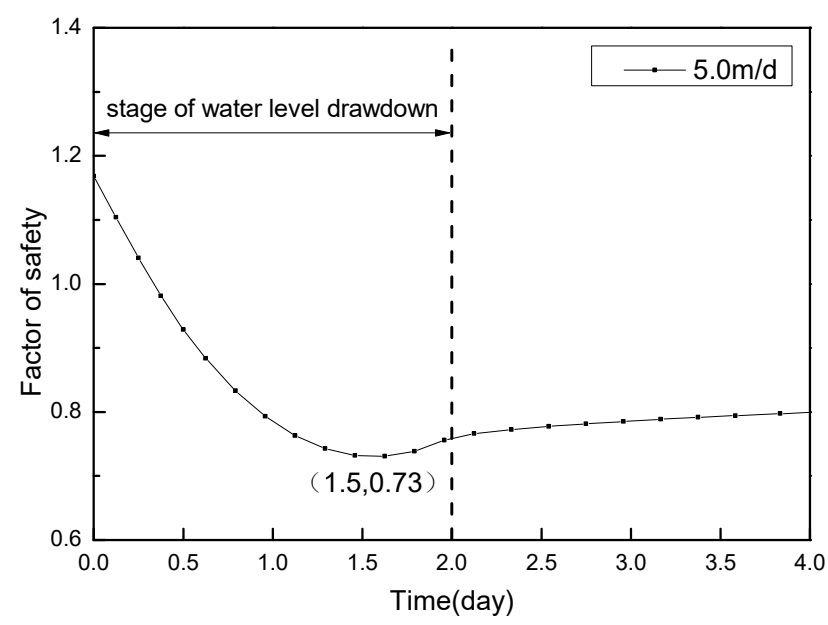

(c). Relationship between safety factor and time when the water level drawdown speed is $5.0 \mathrm{~m} / \mathrm{d}$.

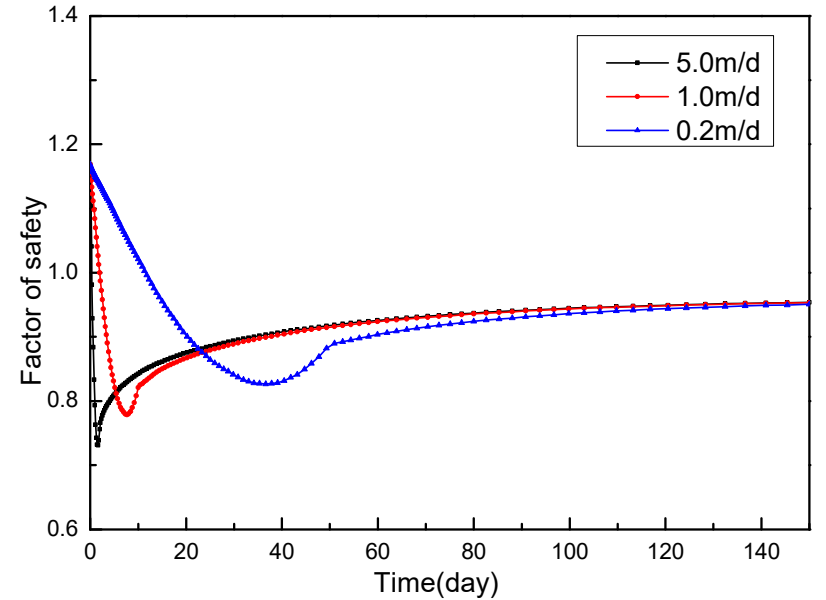

(d). Comparison of the safety factor change with time under different water level drawdown speeds.

Figure 5. Relationship between safety factor and time with the reservoir water level drawdown.

Figure 5(a) to Figure 5(c) present the variation of safety factor with time under different reservoir water level drawdown speeds. It is found that the factor of safety changes from decrease to increase along with the reservoir water level drawdown, and then gradually tends to stabilization. Contrary to the reservoir water level rise, the reservoir water level drawdown resulting in the water flowing from the inside to the outside of the slope, and inducing the hydrodynamic pressure which is not conducive to the stability of the slope. Meanwhile, the flooded area of the slope will gradually decrease with the groundwater drawdown, which is conducive to the stability of the slope. Therefore, because of the great delay time of the process of the groundwater drawdown, resulting in the flooded area decreasing slowly, the factor of safety present a rapid decrease trend. Then the flooded area gradually decreases and the hydrodynamic pressure also gradually decreases with groundwater drawdown, resulting in the factor of safety increases, and trend to stabilization when the water level is the same high on the inside and outside of the slope.

Furthermore, comparison of the minimum value of the safety factor, the value decreases from 0.83 to 0.78 to 0.73 when the drawdown speed of the reservoir water level increases from $0.2 \mathrm{~m} / \mathrm{d}$ to $1.0 \mathrm{~m} / \mathrm{d}$ to $5.0 \mathrm{~m} / \mathrm{d}$, and Figure 5(d) shows the shorter time and lower minimum value of the safety factor arrives with the greater drawdown speed of the reservoir water level. It is also because of the hydrodynamic pressure grows relatively fast and large when the reservoir water level drawdown speed is very higher.

Besides that, the reservoir water level of the minimum safety factor is analyzed, $t$ is the time of the minimum value appears, $T$ is total time of the stage of the reservoir water level drawdown, which the $t / T$ is $0.72,0.75$ and 0.75 respectively. Because the process of reservoir level drawdown is linear, $h_{t}$ is the water level of the minimum value appears, $H$ is total height of the slope, which the $h_{t} / H$ is $0.28,0.25$ and 0.25 correspondingly, and the values match well with Zheng's conclusion[14].

\section{Conclusions}

The slope stability calculation and analysis were carried out based on the numerical modeling of Geostudio. The variation of the slope stability at different times under different water level fluctuation was analyzed considering the seepage and stress coupling effect. It has some reference values for the sliding stability evaluation of slope. The following conclusions were generated.

(1) The slope stability calculation and analysis under different water level fluctuation are carried out. It is indicated that the factor of safety increases with the reservoir water level rises, and then gradually changes from decrease to stabilization. The factor of safety changes from decrease to increase along with the reservoir water level drawdown, and then gradually tends to stabilization.

(2) It is shown that the higher speed of the reservoir water level rising, the more favorable to the stability of slope at the same seepage coefficient. And it should be noted that the slope will probably lose its stability because of the disadvantageous action of the flooded area during the initial stage of water level rising at a low speed $(0.2$ $\mathrm{m} / \mathrm{d})$.

(3) The worse stability of the slope with increasing drawdown speed, the minimum factor of safety has an about $15 \%$ difference between the water level drawdown speed is $0.2 \mathrm{~m} / \mathrm{d}$ and $5.0 \mathrm{~m} / \mathrm{d}$. And there is a minimum factor of safety when the water level is at about $1 / 4$ of the slope height. Therefore, it must be paid an enough attention to discharge water from the reservoir.

\section{References}

1. Sun G H, Zheng H, Tang H M, Dai F C. (2016) Huangtupo Landslide stability under water level fluctuations of the Three Gorges reservoir. Landslides, (13): 1167-1179.

2. Tan L Y, Huang R Q, Pei X J. (2021) Deformation characteristics and inducing mechanisms of a superlarge bedding rock landslide triggered by reservoir 
water level decline in Three Gorges Reservoir area. Chinese Journal of Rock Mechanics and Engineering, 40(02): 302-314.

3. Xiao J F, Li Y A, Hu Y, Zhang S, Cai J M. (2021) Model tests on deformation characteristics of ancient bank landslide under water level fluctuation and rainfall. Rock and Soil Mechanics, 42(02): 471-480.

4. Ding X L, Fu J, Zhang Q H. (2004) Stability analysis of landslide in the south end of fengjie highway bridge with fluctuation of water level of three gorges reservoir. Chinese Journal of Rock Mechanics and Engineering, 23(17): 2913-2919.

5. Liu C H, Chen C X, Feng X T. (2005) Study on mechanism of slope instability due to reservoir water level rise. Rock and Soil Mechanics, 26(5): 769-773.

6. Yang J H, Wang J M, Dong J Y, Liu H D, Wang S W. (2011) Analysis of transient stability of deposits slope in process of reservoir impounding. Rock and Soil Mechanics, 32(s1): 464-470.

7. Lin Y, Deng M L, Li Z J. (2020) Deformation characteristics of Sanmendong landslide in Three Gorges Reservoir area under reservoir water fluctuation. Yangtze River, 51(5): 125-130.

8. Liao H J, Sheng Q, Gao S H, Xu Z P. (2005) Influence of drawdown of reservoir water level on landslide stability. Chinese Journal of Rock Mechanics and Engineering, 24(19): 3454-3458.

9. Wang X W, Xu S J, Dang F N, Chen S Z. Analysis of Stability of Dam Slope during Rapid Drawdown of Reservoir Water Level. Rock and Soil Mechanics, 31(9): 2760-2764.

10. Li Z Z, Zhang Y, Cheng Y J. (2017) Stability analysis of landslide during sudden drawdown of reservoir level. Journal of Guilin University of Technology, 37(3): 489-494.

11. Chen X P, Qian P Y, Liang Z S, Zhang F Z, Wu Q X. (2004) Coupling analysis of heterogeneous earth dam stability of seepage field and stress field. Rock and Soil Mechanics, 25(6):860-864.

12. Liu J, Sun S L, Liu B, Chen Y Y, Wang E X. (2016) Analysis of Seepage and stress coupling effect on stability of unsaturated soil slope. Journal of Hebei University of Engineering(Natural Science Edition), 33(3): 38-42+56.

13. Darkshanamurthy V, Fredlund D, Rahardjo H. (1984). Coupled three-dimensional consolidation theory of unsaturated porous media. Proceedings of the 5th international conference on expansive soils. Adelaide, South Australia, 99-103.

14. Zheng Y R, Shi W M, Kong W X. (2004) Calculation of seepage forces and phreatic surface under drawdown conditions. Chinese Journal of Rock Mechanics and Engineering, 23(18): 3203-3210. 